\title{
Peroxidases Ativadas por Frações Protéicas de Extrato Biológico Eficaz na Proteção do Tomateiro Contra a Mancha Bacteriana
}

\author{
Fábio R. Cavalcanti ${ }^{1}$, Mário Lúcio V. Resende ${ }^{2}$ \& José Tadeu A. Oliveira ${ }^{3}$
}

\author{
${ }^{1}$ Campus Profa. Cinobelina Elvas, Universidade Federal do Piauí, CEP 64900-000, Bom Jesus, PI, Brasil; \\ ${ }^{2}$ Departamento de Fitopatologia, Universidade Federal de Lavras, Cx. Postal 3037, CEP 37200-000, Lavras, MG, Brasil, \\ e-mail: mlucio@ufla.br; ${ }^{3}$ Departamento de Bioquímica e Biologia Molecular, Universidade Federal do Ceará, \\ Cx. Postal 6033, CEP 60451-970, Fortaleza, CE, Brasil
}

Autor para correspondência: Mário Lúcio V. Resende

CAVAlCANTI, F.R., RESENDE, M.L.V. \& OLIVEIRA, J.T.A. Peroxidases ativadas por frações protéicas de extrato biológico eficaz na proteção do tomateiro contra a mancha bacteriana. Fitopatologia Brasileira 32:507-511. 2007.

\begin{abstract}
RESUMO
Uma formulação natural (VLAF) obtida da extração aquosa a frio de pó de tecido necrótico de lobeira (Solanum lycocarpum), infectado por Crinipellis perniciosa (Stahel) Singer, promoveu redução significativa no progresso da mancha foliar bacteriana (Xanthomonas campestris pv. vesicatoria), quando previamente pulverizado em folhas de tomateiro. Duas frações obtidas por precipitação salina, F0/30 e F30/60, apresentaram a maior parte das proteínas do extrato VLAF e foram submetidas à cromatografia de troca catiônica para separação das proteínas contidas nas frações. Os picos não retidos dessa cromatografia foram então submetidos à cromatografia de troca aniônica. Todos os picos, retidos e não retidos das duas cromatografias, foram amostrados e pulverizados sobre plantas de tomate cv. Santa Cruz Kada. Respostas diferenciais de atividade de peroxidases foram obtidas 14 horas após pulverizações. As amostras que induziram os maiores aumentos na atividade de peroxidases nas plantas foram o pico retido em CM-celulose da F0/30 (F0-30CMR) e o pico retido em DEAEcelulose da F30/60 (F30-60DEAER). Os resultados deste estudo indicaram a viabilidade da purificação e da caracterização de proteínas ou carboidratos eliciadores provenientes de VLAF.
\end{abstract}

Palavras-chave adicionais: eliciador, extrato biológico, fracionamento de proteína.

\begin{abstract}
Peroxidases activated by protein fractions of a biological extract useful for tomato protection against bacterial spot

A crude formulation (VLAF) of an aqueous cold extract obtained from Solanum lycocarpum necrotic tissue infected by Crinipellis perniciosa was showed capable of reducing disease progress of tomato bacterial leaf spot, when previously sprayed on tomato plants. The fractions F0/30 and F30/60 were achieved by saline precipitation and they showed highest amounts of proteins from VLAF. The fractions were submitted to cationic exchange chromatography for protein scanning. Non-retained peaks from this first chromatography were submitted to an anionic exchange chromatography. Both retained and non-retained peaks from both ion exchanges were sampled and sprayed on cv. Santa Cruz Kada tomatoes. Contrasting peroxidase activities were observed 14 hours after sprayings. The samples that produced the highest peroxidase increases were the retained peak in cationic exchange from F0/30 (F0-30CMR) and the retained peak in anionic exchange chromatography from F30/60 (F30-60DEAER). Our results indicate the viability of searching for protein- or carbohydratederived molecules from VLAF aqueous extract.
\end{abstract}

Additional keywords: elicitor, protein fractioning, natural extract.

Respostas fisiológicas de plantas ao estresse ambiental baseiam-se em sinalização molecular. Os eliciadores são uma classe de sinalizadores que estimula resposta de defesa nas plantas e são reconhecidos por receptores, usualmente presentes na membrana plasmática, ativando uma cascata de transdução de sinais que levará à indução de uma rede de mecanismos de defesa (Hammond-Kosack \& Parker, 2003). Várias classes de compostos estruturalmente distintos, como oligossacarídeos, moléculas lipofílicas, glicoproteínas e peptídeos agem como sinais químicos que são percebidos pelas plantas e induzem elementos envolvidos na resposta de defesa. Esses eliciadores podem ser classificados como exógenos, quando oriundos do patógeno invasor, ou endógenos, quando provenientes da própria planta, em decorrência do ataque do patógeno (Shibuya \& Minami, 2001). A mancha bacteriana do tomateiro, cujo agente etiológico é Xanthomonas campestris pv. vesicatoria (Doidge) Dye, é considerada uma das bacterioses de ampla incidência no país, podendo ter seu progresso diminuído pela pulverização de eliciadores na promoção de indução de resistência em plantas de tomateiro (Cavalcanti et al., 2006).

As peroxidases (POX; EC 1.11.1.7) de planta são glicoproteínas que contêm um grupamento heme em sua estrutura e possuem a função básica de catalisar a oxidação do peróxido de hidrogênio a partir de numerosas 
espécies de substratos orgânicos e inorgânicos, tais como ascorbato, nitrito, indol-aminas e outros (Zámocky et al., 2001). Defesa da planta contra patógenos, formação de lignina, metabolismo da auxina, biossíntese de etileno, respiração, processos intermediados por luz, crescimento e senescência são alguns exemplos de eventos fisiológicos nos quais existe a participação das peroxidases. A oxidação dos álcoois hidroxicinâmicos, precursores imediatos da lignina, é catalisada por POXs, resultando na produção de radicais fenoxi-mesoméricos que reagem espontaneamente durante a deposição de lignina na parede celular (Datta \& Muthukrishnan, 1999).

O objetivo deste estudo foi iniciar e direcionar processos de prospecção, separação e purificação de uma ou mais frações de natureza protéica, provenientes de um extrato aquoso a frio ('VLAF', vassoura-lobeira-água-frio) de pó de tecido caulinar de 'lobeira' (Solanum lycocarpum) infectado por Crinipellis perniciosa (Stahel) Singer, capazes de promover o aumento de POX a partir de sua pulverização em plantas sadias de tomateiro cv. Santa Cruz Kada. As POXs são classificadas como proteínas relacionadas à patogênese, e, no presente estudo, foram adotadas como marcadores de resposta de indução de defesa em folhas de tomateiro tratadas com as frações eliciadoras.

Sementes de tomate cv. Santa Cruz Kada (Isla Sementes Ltda.), foram imersas em álcool etílico a $1 \% \mathrm{v} / \mathrm{v}$ e hipoclorito de sódio $0,1 \% \mathrm{v} / \mathrm{v}$, por um min, e então lavadas com água destilada e germinadas em recipientes de 400 $\mathrm{mL}$, contendo areia textura média exaustivamente lavada e esterilizada. Após a emergência, as plântulas foram regadas diariamente com 1/10 da solução nutritiva de Hoagland (Hoagland \& Arnon, 1950). Para o experimento de avaliação de progresso de doença, plantas foram transferidas para vasos de 3 litros, contendo areia textura média, argila e matéria orgânica, na proporção $(3: 1: 1)$, sendo mantidas em casa de vegetação com média de temperatura dia/noite de $28 / 24{ }^{\circ} \mathrm{C}$, umidade relativa de $53 / 85 \%$, fotoperíodo de 12 $\mathrm{h}$, e uma média de densidade máxima de fluxo de fótons de $310-400 \mu \mathrm{mol} \mathrm{m}{ }^{-2} \mathrm{~s}^{-1}$, medidos na planta (IRGA modelo LCA-4, Hoddesdon, UK).

Tecido caulinar de lobeira, densamente infectado e necrosado por $C$. perniciosa, foi coletado para secagem a $60^{\circ} \mathrm{C}$ por $24 \mathrm{~h}$ com posterior trituração seguida de moagem. Tecidos caulinares de ramos sadios também foram coletados para o mesmo fim, sendo utilizados como controle. O pó obtido dos tecidos necrosado e sadio foi armazenado sob refrigeração a $4^{\circ} \mathrm{C}$. Cento e vinte gramas do pó obtido do tecido necrosado foram divididos em 8 alíquotas de $15 \mathrm{~g}$, com cada alíquota sendo ressuspensa em $50 \mathrm{~mL}$ de água em erlenmeyer de $250 \mathrm{~mL}$. As suspensões sofreram agitação de $130 \mathrm{rpm}$ durante 5 horas. O extrato (VLAF) foi filtrado a vácuo, sendo a amostra congelada a $-20^{\circ} \mathrm{C}$.

$\mathrm{O}$ isolamento de Xanthomonas campestris pv. vesicatoria foi realizado a partir de folhas naturalmente infectadas de tomateiro (Lycopersicon esculentum Mill.), em meio 523 de Kado \& Heskett (1970), incubado à temperatura de $28^{\circ} \mathrm{C}$. Após lavagem e centrifugação, a concentração da suspensão bacteriana foi ajustada em espectrofotômetro para $\mathrm{A}_{540}=0,20$, correspondendo a aproximadamente $10^{11}$ UFC L $~^{-1}$. Com isso, copas de plantas de tomateiro cv. Santa Cruz Kada com 15 dias após semeadura foram pulverizadas com VLAF, com o pó de tecido sadio (controle), com acibenzolar-S-metil (Bion $\left.{ }^{\circledR} ; 0,2 \mathrm{~g} \mathrm{~L}^{-1}\right)$ e água destilada até o ponto de escorrimento. O experimento foi delineado em blocos casualizados, com três blocos e parcela experimental de quatro plantas por vaso de $3 \mathrm{~L}$. Após quatro dias, as plantas foram inoculadas, via spray foliar, com a suspensão de $X$. campestris pv. vesicatoria, e avaliadas aos 3, 6, 9, 12,15 e 20 dias após a inoculação (DAI). Para se avaliar a eficiência dos extratos testados na proteção de plantas, foi adaptada uma escala de notas baseada em Sidhu \& Webster (1977). O cálculo da Área Abaixo da Curva de Progresso de Doença (AACPD) seguiu a equação de Campbell \& Madden (1990).

Amostras de VLAF foram submetidas à precipitação por sulfato de amônio a 0-30\% (F0-30) e 30-60\% (F30-60) de saturação, durante $12 \mathrm{~h}$ à temperatura de $4^{\circ} \mathrm{C}$. Em seguida, os volumes foram centrifugados $5000 \mathrm{~g}$ por $30 \mathrm{~min}$, os precipitados ressuspensos em água grau Milli-Q, em menor volume possível ( $\cong 10 \mathrm{~mL}$ ), e dialisados contra água Milli-Q em membrana de $12,5 \mathrm{kDa}$, durante $24 \mathrm{~h}$. As amostras foram preparadas (F0/30 e F30/60) para pulverização em folhas de tomateiro de 15 dias após plantio. As frações obtidas da precipitação salina e diálise, F0/30 e F30/60, foram submetidas à cromatografia de troca catiônica (resina de CM-celulose) em coluna $3 \times 1,5 \mathrm{~cm}$. A eluição do material

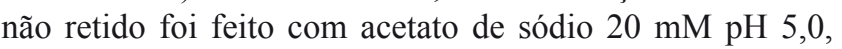
enquanto as proteínas retidas foram eluídas após aplicação de um gradiente de $\mathrm{NaCl}(0-1 \mathrm{M})$. Picos não retidos da cromatografia de troca catiônica foram concentrados por secagem a frio $\left(4^{\circ} \mathrm{C}\right)$ e submetidos à cromatografia de troca aniônica (resina de DEAE-celulose) em coluna 7 x 1,5 cm, equilibrada com Tris-HCl $25 \mathrm{mM}, \mathrm{pH}$ 7,5. A remoção do material não retido foi feita com o tampão de equilíbrio, enquanto a eluição do material retido foi obtida sob gradiente contínuo de $\mathrm{NaCl}(0-1 \mathrm{M})$. Todas as frações obtidas foram lidas a $280 \mathrm{~nm}$.

Plantas de tomateiro, 15 dias após semeadura, foram pulverizadas com frações (F0/30 e F30/60) de VLAF e amostras de picos cromatográficos retidos (F0-30CMR, F30-60CMR, F0-30DEAEPIII, F0-30DEAEPIV, F3060DEAER) e não retidos (F0-30DEAEPI, F0-30DEAEPII, F30-60DEAENR), até o ponto de escorrimento. As amostras foram pulverizadas em três plantas, com parcela de uma planta por recipiente de $400 \mathrm{~mL}$. Folhas de plantas tratadas e de testemunhas expostas à água destilada (controle) foram coletadas $14 \mathrm{~h}$ após pulverizações (HAP). Em seguida, as folhas foram congeladas em nitrogênio líquido e imediatamente utilizadas para determinações bioquímicas.

O material foliar foi homogeneizado em $3 \mathrm{~mL}$ de tampão acetato de sódio $50 \mathrm{mM}$ pH 5,2 contendo EDTA $0,1 \mathrm{mM}$ durante $5 \mathrm{~min}$, em bandeja com gelo. $\mathrm{O}$ teor de 
proteína solúvel contida nos extratos foi aferido pelo ensaio de Bradford (1976), usando um padrão de albumina sérica bovina (BSA). A atividade de peroxidases foi determinada pela adição de $25 \mu \mathrm{L}$ do extrato enzimático ajustado para 2 $\mathrm{mL}$ de uma solução contendo acetato de sódio $50 \mathrm{mM} \mathrm{pH}$ 5,2 , guaiacol $20 \mathrm{mM}$ e peróxido de hidrogênio $20 \mathrm{mM}$. Após incubação em $30^{\circ} \mathrm{C}$ por $10 \mathrm{~min}$, a absorbância foi medida a $480 \mathrm{~nm}$ (Urbanek et al., 1991). Uma unidade de atividade de POX foi expressa como variação de absorbância $\left(\mathrm{A}_{480}\right)$ por miligrama de proteína solúvel por minuto $\left(\mathrm{UA} \mathrm{mgP}^{-1} \mathrm{~min}^{-}\right.$ 1). A determinação de açúcares redutores foi conduzida pelo ensaio colorimétrico de Somogyi-Nelson, usando o cobre divalente como agente oxidante (Nelson, 1944). Eletroforese em gel de poliacrilamida (SDS-PAGE) foi realizada de acordo com Laemmli (1970), usando-se um gel de separação de $12,5 \%$ sobreposto por um gel de empilhamento de $5 \%$. Extratos enzimáticos foram preparados em presença de azul de bromofenol e glicerol. Um volume referente a um valor fixo de $10 \mu \mathrm{g}$ de proteína de cada amostra foi adicionado aos poços do gel de empilhamento. Proteínas em estudo foram visualizadas por coloração com prata (Blum et al., 1987) após a etapa de fixação de $15 \mathrm{~h}$ em uma solução de $40 \%$ etanol e $10 \%$ ácido acético. Massas moleculares foram calculadas pelo software 'Quantity One' (Bio-Rad, USA).

O tratamento com VLAF proporcionou $42,5 \%$ de proteção (Figura 1) e foi estatisticamente igual ao tratamento com ASM $\left(\right.$ Bion $\left.{ }^{\circledR}\right)$, que, por sua vez, conferiu proteção de 46,2\%. O controle do VLAF (extrato do pó de

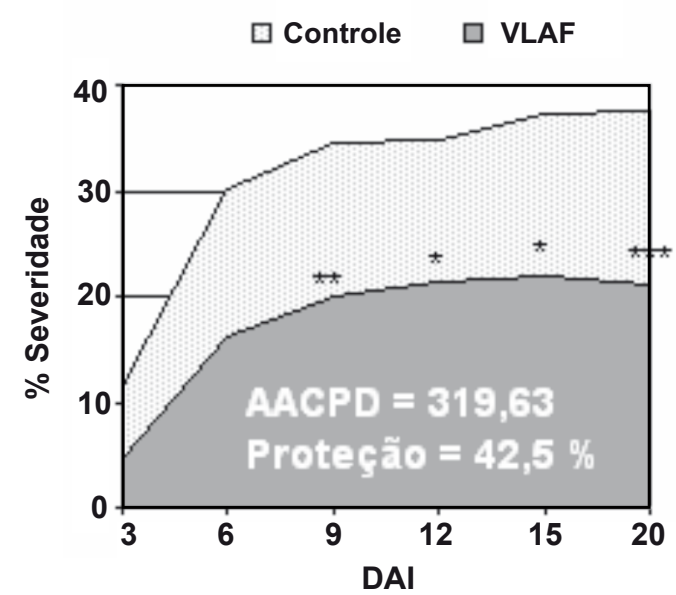

FIG. 1 - Eficácia do extrato aquoso a frio de vassoura de $C$. perniciosa (VLAF) obtido de lobeira na redução da severidade da mancha bacteriana em folhas de tomateiro cv. S. Cruz Kada ao longo de 20 dias após inoculação (DAI). O tratamento foi pulverizado sobre as folhas 15 dias após plantio, sendo as mesmas plantas inoculadas quatro dias após. Plantas pulverizadas com água destilada foram definidas como controle. Diferenças significativas (teste $t$ de Student) entre VLAF e os respectivos controles são mostradas em função dos níveis de significância $\left(^{*}\right) \rho=0.05,(* *)$ $\rho=0.01$ e $(* * *) \rho=0.001$. ramos sadios de lobeira) não promoveu redução significativa da AACPD em plantas inoculadas, ao longo do período experimental. Existem inúmeros relatos de obtenção de eliciadores a partir de material biológico. Basse et al. (1992) obtiveram pequenos glicopeptídeos a partir da digestão de uma invertase de levedura por $\alpha$-quimiotripsina, que foram ativos na eliciação de etileno e respostas de atividade de amônia-liases de fenilalanina (PAL) em células cultivadas de tomateiro. Chang et al. (1995) verificaram acúmulo de mRNA de uma quitinase de ervilha eliciada por quitosana de Fusarium sp. Bailey (1995) conseguiu purificar uma proteína $(22,5 \mathrm{kDa})$ de filtrado de cultura de Fusarium oxysporum que induziu etileno e necrose em folhas de Erythroxylum coca. No Brasil, foi caracterizado um eliciador de fitoalexina em soja a partir de urediniósporos de Hemileia vastatrix (Guzzo \& Moraes, 1997). Também, a ação ativadora de defesa em um extrato aquoso proveniente de massa seca de Lentinula edodes foi comprovada em plantas de pepino inoculadas com Colletotrichum lagenarium. Neste mesmo trabalho, frações protéicas do extrato aquoso e de um pico eluído de cromatografia de troca iônica foram efetivas na proteção de plântulas de pepino, com aumento de atividade de peroxidases de fenóis (Di Piero et al., 2006).

Assim, numa etapa seguinte, os produtos de separação provenientes do fracionamento de VLAF foram pulverizados no tomateiro. Plantas pulverizadas com as frações F0/30 e F30/60, responderam com aumento de atividade de POX. Plantas pulverizadas com alíquotas dos picos F0-30CMR e F30-60DEAER responderam com números significativamente maiores de atividade POX a 14 HAP, chegando a atingir $430 \%$ e $370 \%$ do controle, respectivamente. Plantas expostas aos picos retidos F030DEAEPIII e F0-30DEAEPIV também promoveram ativação de POX (Figura 2). Plantas pulverizadas com acibenzolar-S-metil (Bion $\AA$, 0,2 $\mathrm{g} \mathrm{L}^{-1}$ ), responderam, em média, com $0,8 \mathrm{UA} \mathrm{mgP}^{-1} \mathrm{~min}^{-1}$ de POX, a 14 HAP.

Alíquotas de picos e frações contendo atividade eliciadora de POX em tomateiro foram submetidas à eletroforese, sob condições desnaturantes, em gel de poliacrilamida. Os perfis estão apresentados na Figura 3. Alíquotas de picos que se mostraram mais promissores na eliciação de respostas POX em tomateiro a 14 HAP, F0-30CMR e F30-60DEAER, foram as que evidenciaram maior quantidade e diversidade de proteínas. Considerando os níveis de açúcares medidos nas frações, o pico F3060DEAER revelou altas concentrações, enquanto que F030CMR mostrou baixíssimos teores de açúcares redutores (Figura 2C). Este último pico (F0-30CMR) destaca-se por apresentar maior possibilidade de possuir um eliciador protéico intrínseco, com menor indício de eliciação glicídica, comparativamente a F30-60DEAER.

Trabalhos envolvendo purificação de eliciadores têm a finalidade da utilização do seu princípio ativo em algum produto comercial. Muito conhecido é o aproveitamento da harpina, como um fator de patogenicidade protéico sintetizado por Erwinia amylovora (Jin et al., 1997), cujo 

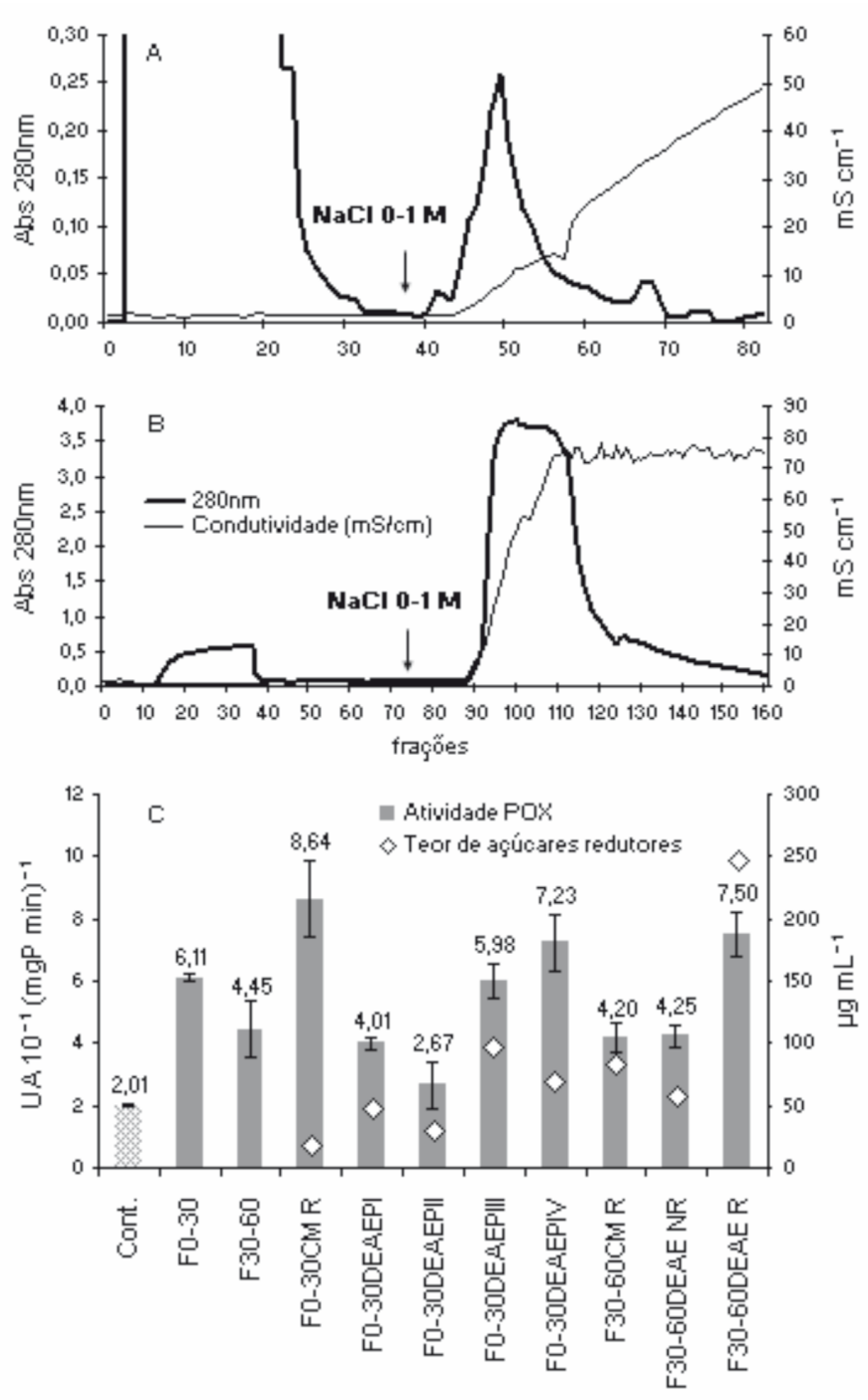

M1

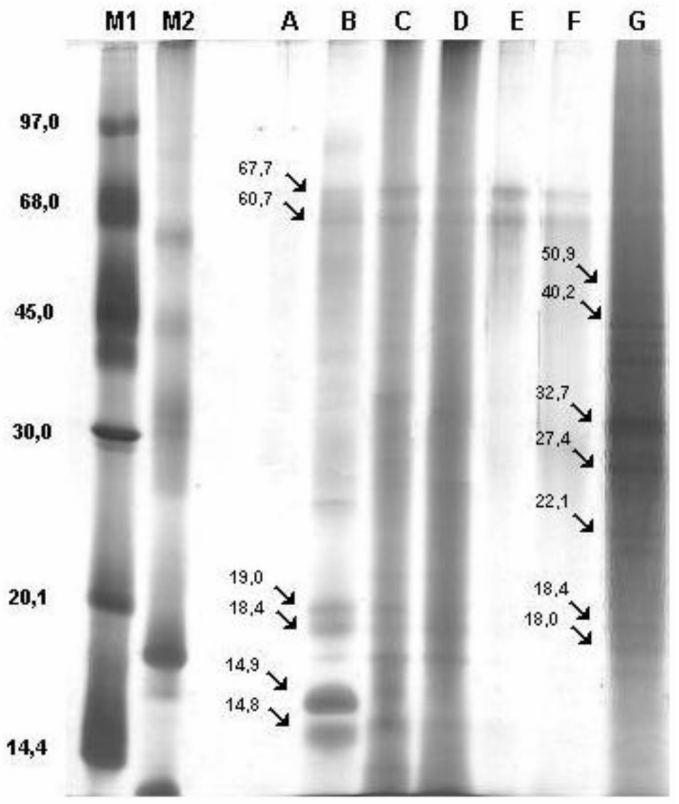

FIG. 2 - A. Cromatografia de troca catiônica da fração F0/30, obtido a partir de extrato aquoso a frio de vassoura de $C$. perniciosa (VLAF). O material foi aplicado em coluna de CM-celulose ( 3 x 1,5 cm). Tampão de equilíbrio: acetato de sódio $20 \mathrm{mM}, \mathrm{pH}$ 5,0. Eluição em gradiente $(0-1 \mathrm{M})$ de $\mathrm{NaCl}$, indicado pela condutividade $\left(\mathrm{mS} \mathrm{cm}{ }^{-1}\right)$. Fração: 3,1 mL. Fluxo: $93 \mathrm{~mL} \mathrm{~h}^{-1}$. Quantidade de proteína aplicada: 11,66 mgP; B. Cromatografia de troca aniônica da fração $\mathrm{F} 30 / 60$. O pico não retido em CM-celulose foi preparado e aplicado em coluna de DEAE-celulose ( 7 x 1,5 cm). Tampão de equilíbrio: Tris$\mathrm{HCl} 25 \mathrm{mM}$, pH 7,5. Eluição em gradiente (0-1M) de $\mathrm{NaCl}$. Fração: 2,9 mL. Fluxo: $50 \mathrm{~mL} \mathrm{~h}^{-1}$; C. Atividade de peroxidases de guaiacol (POX) e teores de açúcares redutores (losangos, $\mu \mathrm{g} \mathrm{mL}^{-1}$ ) em folhas de tomateiro $\mathrm{cv}$. Santa Cruz Kada, 14 HAP. Controles foram pulverizados com água destilada. Barras de erros indicam desvio padrão $(n=3)$.

FIG. 3 - Eletroforese em gel de poliacrilamida (SDSPAGE) de frações provenientes do extrato aquoso a frio de vassoura de $C$. perniciosa (VLAF). $\mathrm{M}=$ Marcador (kDa). Poço A. F30-60CMR, B. F0-30CMR, C. F3060DEAENR, D. F0-30DEAEPI, E. F0-30DEAEPII, F. F0-30DEAEPIII, G. F30-60DEAER. Setas indicam bandas protéicas de maior destaque. Proteínas em estudo foram visualizadas por coloração com prata. Quantidade de proteína aplicada em cada poço: $\cong 5 \mu \mathrm{g}$. 
gene foi clonado em E. coli para produção em larga escala da proteína. O pacote comercial Messenger ${ }^{\circledR}$ utiliza este esquema biológico para induzir resistência. Outros produtos valem-se, não de produtos protéicos, mas de eliciadores como quitosana e oligossacarídeos. Estudos subseqüentes devem ser conduzidos para averiguar se existe alguma molécula eliciadora, proteína ou oligossacarídeo, proveniente de extrato aquoso de pó de tecido necrótico de $S$. lycocarpum (VLAF), que possa ser viável para a composição de um produto comercial, no futuro.

Em conclusão, o extrato aquoso a frio de vassoura de C. perniciosa, obtido de lobeira, pode ser fracionado por precipitação salina e cromatografia de troca iônica. As frações obtidas são capazes de eliciar diferencialmente a atividade de peroxidases de guaiacol quando pulverizadas em plantas de tomateiro. Além disso, há uma forte possibilidade de os picos F0-30CMR e F30-60DEAER, provenientes do VLAF, apresentarem uma ou mais proteínas capazes de eliciar respostas de defesa no tomateiro, via esquemas simples de purificação.

\section{AGRADECIMENTOS}

À Fundação Cearense de Apoio ao Desenvolvimento Científico e Tecnológico - FUNCAP e ao Conselho Nacional de Desenvolvimento Científico e Tecnológico - CNPq pelo apoio financeiro.

\section{REFERÊNCIAS BIBLIOGRÁFICAS}

BAILEY, B.A. Purification of a protein from culture filtrates of Fusarium oxysporum that induces ethylene and necrosis in leaves of Erythroxylum coca. Phytopathology 85:250-255. 1995.

BASSE, C.W., BOCK, K. \& BOLLER, T. Eliciadors and supressors of defense response in tomato cells. Journal of Biological Chemistry 267:10258-10264. 1992.

BLUM, H., BEIER, H. \& GROSS, H.J. Improved silver staining of plant proteins, RNA and DNA in polyacrylamide gels. Electrophoresis 8:93-99. 1987.

BRADFORD, M.M. A rapid and sensitive method for the quantitation of micrograms quantities for proteins utilizing the principle of protein-dye binding. Analytical Biochemistry 72:248254. 1976.

CAVALCANTI, F.R., RESENDE, M.L.V., ZACARONI, A.B., RIBEIRO JUNIOR, P.M., COSTA, J.C.B \& SOUZA, R.M. Acibenzolar-S-Metil e Ecolife ${ }^{\circledR}$ na indução de respostas de defesa do tomateiro contra a mancha bacteriana (Xanthomonas vesicatoria). Fitopatologia Brasileira 31:372-380. 2006.

CAMPBELL, C.L. \& MADDEN, L.V. Introduction to plant disease epidemiology. New York NY. John Wiley \& Sons. 1990.

CHANG, M., HOROVITZ, D., CULLEY, D. \& HADWIGER, L.A. Molecular cloning and characterization of a pea chitinase gene expressed in response to wounding, fungal infection and the elicitor chitosan. Plant Molecular Biology 28:105-111. 1995.

DATTA, S.K. \& MUTHUKRISHNAN, S. Pathogenesis-related proteins in plants. Boca Raton. CRC Press. 1999.

DI PIERO, R.M., WULFF, N.A. \& PASCHOLATI, S.F. Partial purification of elicitors from Lentinula edodes basidiocarps protecting cucumber seedlings against Colletotrichum lagenarium. Brazilian Journal of Microbiology 37:169-174. 2006.

GUZZO, S.D. \& MORAES, W.B.C. Purificação e caracterização parcial de um eliciador de fitoalexina em soja, a partir de urediniósporos de Hemileia vastatrix. Fitopatologia Brasileira 22:396-402. 1997.

HAMMOND-KOSACK, K. \& PARKER, J. Deciphering plantpathogen communication: fresh perspectives for molecular resistance breeding. Current Opinion in Biotechnology 14:177193. 2003.

HOAGLAND, D.R.. \& ARNON, D.I. The water culture method for growing plants without soil. Berkeley CA, USA. California Agricultural Experiment Station, University of California. 1950.

JIN, Q.L., LIU, N.Z., QIU, J.L., LI, D.B. \& WANG, J.A truncated fragment of harpin Pss induces systemic resistance to Xanthomonas campestris pv. oryzae in rice. Physiological and Molecular Plant Pathology 51:243-257. 1997.

KADO, C.I. \& HESKETT, M.G. Selective media for isolation of Agrobacterium, Corynebacterium, Erwinia, Pseudomonas and Xanthomonas. Phytopathology 60:96-97. 1970.

LAEMMLI, U.K. Cleavage of structural proteins during the assembly of the head bacteriophage T4. Nature 227:680-685. 1970.

NELSON, N. A photometric adaptation of the Somogyi method for the determination of glucose. The Journal of Biological Chemistry 153:375-381. 1944.

SIDHU, G.S. \& WEBSTER, J.M. The use of amino acid fungal auxotrophs to study the predisposition phenomena in the root-knot: wilt fungus disease complex. Physiological Plant Pathology 11:17127. 1977.

SHIBUYA, N. \& MINAMI, E. Oligosaccharides signalling for defense responses in plants. Physiological and Molecular Plant Pathology 59:223-233. 2001.

URBANEK, H., KUZNIAK-GEBAROWSKA, E. \& HERKA H. Elicitation of defense responses in bean leaves by Botrytis cinerea polygalacturonase. Acta Physiologia Plantarum 13:43-50. 1991.

ZÁMOCKY, M., REGELSBERGER, G., JAKOPITSCH, C. \& OBINGER, C. The molecular peculiarities of catalase-peroxidases. FEBS Letters 492:177-182. 2001. 